\title{
Skills Required for Secondary Education Teachers in Inclusive Settings
}

\author{
Irene Wanja Muiruri, Kiptoo Wilson
}

\begin{abstract}
Despite the government's best efforts, the problem of discrimination among kids with special educational needs continues to grow. Students with learning disabilities have not been supplied with the necessary resources, physical facilities, or equipment to meet their specific needs, as their colleagues have. As a result, the primary goal of this research was to find out skills required for secondary education teachers in inclusive settings. The research method to be adopted in this study was quantitative methods. The research's target population was 84 secondary school teachers. The respondents were drawn from the four secondary schools in Keiyo North Sub-County with inclusive education. Questionnaires were used to collect data from teachers. Quantitative analysis entailed the use of descriptive statistics such as percentages and frequency distribution tables. The Statistical Package for Social Scientists (SPSS) software version 25 was used to interpret the data. Presentation of data was by use of tables, pie charts and descriptions. The study concluded that teachers in an inclusive school should have a strong vision that all children can learn and believe in their abilities. Teachers should possess skills in classroom management for inclusive education. They should also possess techniques of assessment in the implementation of inclusive education programs, a study has found. The study recommends that the teachers receive in-service training to ensure that they have a strong vision of all children being able to learn and believe in their kids' talents. For inclusive education, teachers need to have classroom management abilities. Every day in the classroom, teachers should be able to be very structured. Teachers must encourage both ordinary and disabled students to have a positive perception.
\end{abstract}

Key words: teachers, skills required, secondary education, inclusive setting

\section{INTRODUCTION}

$\mathrm{I}$ nclusive learning implies that every child in schools has equal learning possibilities notwithstanding the different cultural, social and learning backgrounds (Sharma, Shaukat \& Furlonger, 2015). Individuals with disabilities have faced discrimination and barriers that keep them out of society on an equal footing with others every day (Hussain, Lone \& Bhat, 2018). There are currently many challenges affecting the implementation of inclusive education worldwide (Kiplagat, Syonthi \& Situma, 2019).

Despite the emphasis on inclusive learning, many teachers still have reservations about include students with special needs in general education classes. Newton, Janelle \& Yvonne (2014) study showed that both secondary and primary school teachers have similar perceptions towards inclusive leaning with either some having negative and others positive. Wiggins (2012) noted a significant association between secondary school teachers' perceptions towards inclusion and classroom environment. According to Mngo and Mngo (2018), teachers who have taught in inclusive settings have more positive views toward inclusive learning than those who have not. According to Davis (2019), teachers have a more positive opinion about mainstreaming than inclusion. Varcoe and Boyle (2014) indicated that training in special education reduces the concerns on having in-service regarding inclusive education. Round, Subban, and Sharma (2016) found that instructors who received special education training have higher positive attitudes regarding implementing inclusive education.

Despite previous studies done and despite the undying government's efforts to control exclusion among children who need special education, this issue has constantly been on the increment. Therefore, this study sought to investigate the skills required for secondary education teachers in inclusive settings at secondary schools in the Keiyo North sub-county.

\section{RESEARCH METHODOLOGY}

Quantitative research method was used. Quantitative research is the process of collecting and analyzing numerical data (Apuke, 2017). Quantitative data included open and close-ended questions in the questionnaire.

The research's target population was 84 secondary school teachers. The respondents were drawn from the 4 secondary schools in Keiyo North Sub-County with inclusive education. The respondent's age was between age of 25 to 60 years. The male respondents were 42 while the female were 42 participants. This was achieved by requesting the five schools to provide 21 teachers with gender balance.

Questionnaires were used to collect data from teachers. A relevant link for completing an online questionnaire was provided to the teachers via email. The collected data was analyzed using quantitative methods. Quantitative analysis entailed the use of descriptive statistics such as percentages and frequency distribution tables. Data analysis was done using Statistical Package for Social Scientists (SPSS) software version 25. Presentation of data was by use of tables, pie charts and descriptions.

\section{FINDINGS}

\section{Response Rate}

The study used quantitative research method. Questionnaires were used to collect data from teachers. The collected data were analyzed using quantitative methods entailing the use of 
descriptive statistics such as percentages and frequency distribution tables. Data analysis was done using Statistical Package for Social Scientists (SPSS) software version 26. Presentation of data was by the use of tables, pie charts and descriptions. The research's target population were 84 secondary school teachers drawn from the 4 secondary schools in Keiyo North Sub-County with inclusive education. The researcher distributed a total of 84 questionnaires to the sample population as presented in Table 1.

Table 1: Response Rate

\begin{tabular}{|c|c|c|}
\hline Category & Frequency & Percentage \\
\hline Responses & 77 & 91.7 \\
\hline Non-Responses & 7 & 8.3 \\
\hline Total & $\mathbf{8 4}$ & $\mathbf{1 0 0}$ \\
\hline
\end{tabular}

From Table 1 it was showed that a total of 77 questionnaires were filled representing $91.7 \%$ response rate while $7(8.3 \%)$ were not returned and others were not entirely filled. The response rate to the research study was good. According to Kombo and Tromp (2009), responses from a research study with a response rate of $50 \%$ are satisfactory, $60 \%$ are good, and $70 \%$ are exceptional. As a result, the study response rate was outstanding, and the valid questionnaires used for data analysis totaled 77 .

\section{BACKGROUND CHARACTERISTICS OF THE RESPONDENTS}

\section{Gender of the Respondents}

The study sought to establish the gender of the respondents. Figure 1 showed the gender of the respondents.

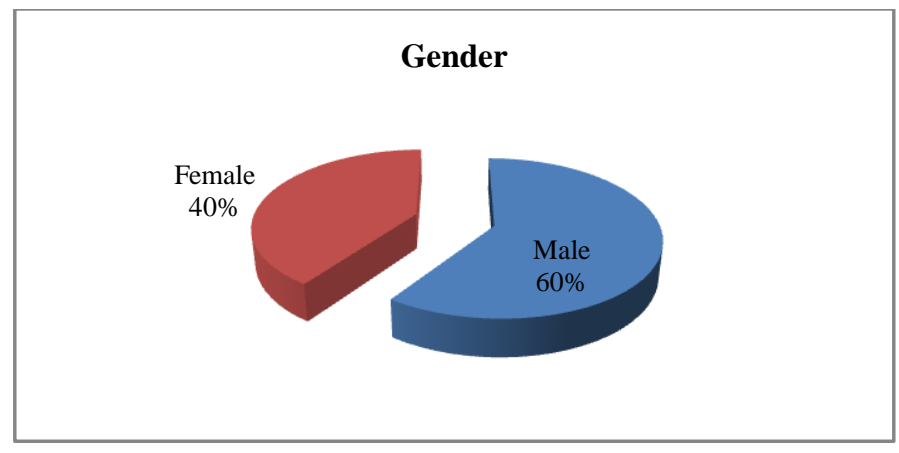

Figure 1: Gender of the Respondents

The study findings in Figure 1 showed that majority of respondents were male at $60 \%$ compared to female who were $40 \%$ as shown in Figure 1. This implies that gender representation was evenly propositional and the views under the study were representative of both genders, however male respondents were marginally more than their female colleagues.

\section{Age Bracket of the Respondents}

Based on perception, different age groups seem to have varying opinions on a range of issues. Against that backdrop, this research asked the respondents to specify their age bracket. Table 2 showed correspondents' age distribution outcomes.

Table 2: Respondents Age Bracket

\begin{tabular}{|c|c|c|}
\hline Category & Frequency & Percentage \\
\hline $25-35$ years & 72 & 93.5 \\
\hline $36-45$ years & 5 & 6.5 \\
\hline Total & $\mathbf{7 7}$ & $\mathbf{1 0 0}$ \\
\hline
\end{tabular}

The results in Table 2 showed that $72(93.5 \%)$ respondents were aged between 25 and 35 years, while 5(6.5\%) were aged between 36 and 45 years. This reveals that most of the teachers in Keiyo North Sub-County secondary schools are youthful.

\section{Highest Education Level of the Respondents}

The researcher also sought to determine the education level of the respondents. Table 3 presents the study results.

Table 3: Respondents Highest Education Level

\begin{tabular}{|c|c|c|}
\hline Category & Frequency & Percentage \\
\hline Diploma & 6 & 7.8 \\
\hline Undergraduate Degree & 68 & 88.3 \\
\hline Masters & 3 & 3.9 \\
\hline Total & $\mathbf{7 7}$ & $\mathbf{1 0 0}$ \\
\hline
\end{tabular}

The results in Table 3 showed that most of the respondents had attained undergraduate degree level at 68(49) that was closely followed by respondents with diploma at $6(7.8 \%)$ of the respondents while $3(3.9 \%)$ had attained master's level. This implies that most of the teachers in Keiyo North SubCounty secondary schools are undergraduate level.

\section{Types of the Learners Disabilities}

The study sought to establish the teacher's response on the types of the learners' disabilities. The study results are presented on Figure 2.

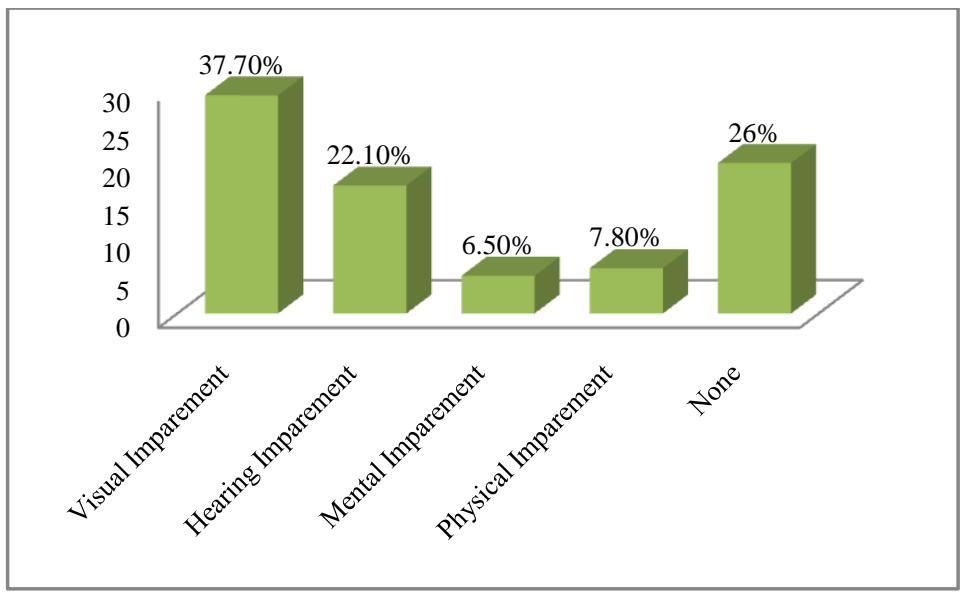

Figure 2: Types of Learners Disabilities 
As shown in Figure 2, 37.7\% of the respondents indicated that students have visual impairment, $22.1 \%$ indicated students have hearing impairment, $6.5 \%$ indicated students have mental impermanent and $7.8 \%$ indicated students have physical impairment while $26 \%$ indicated that students have no disabilities. This implies that majority of the teachers involved in the study believed that majority of the students were faced with visual impairment disability in their schools.
Thus, visual impairment is the major disability in Keiyo North Sub-County secondary schools.

Skills Required for Secondary Education Teachers in Inclusive Settings

The study sought to find out skills required for Secondary Education Teachers in Inclusive Settings at secondary schools in Keiyo North Sub-County, Elgeyo-Marakwet County, Kenya. The study results are presented in Table 4.

Table 4 Skills Required for Secondary Education Teachers in Inclusive Settings

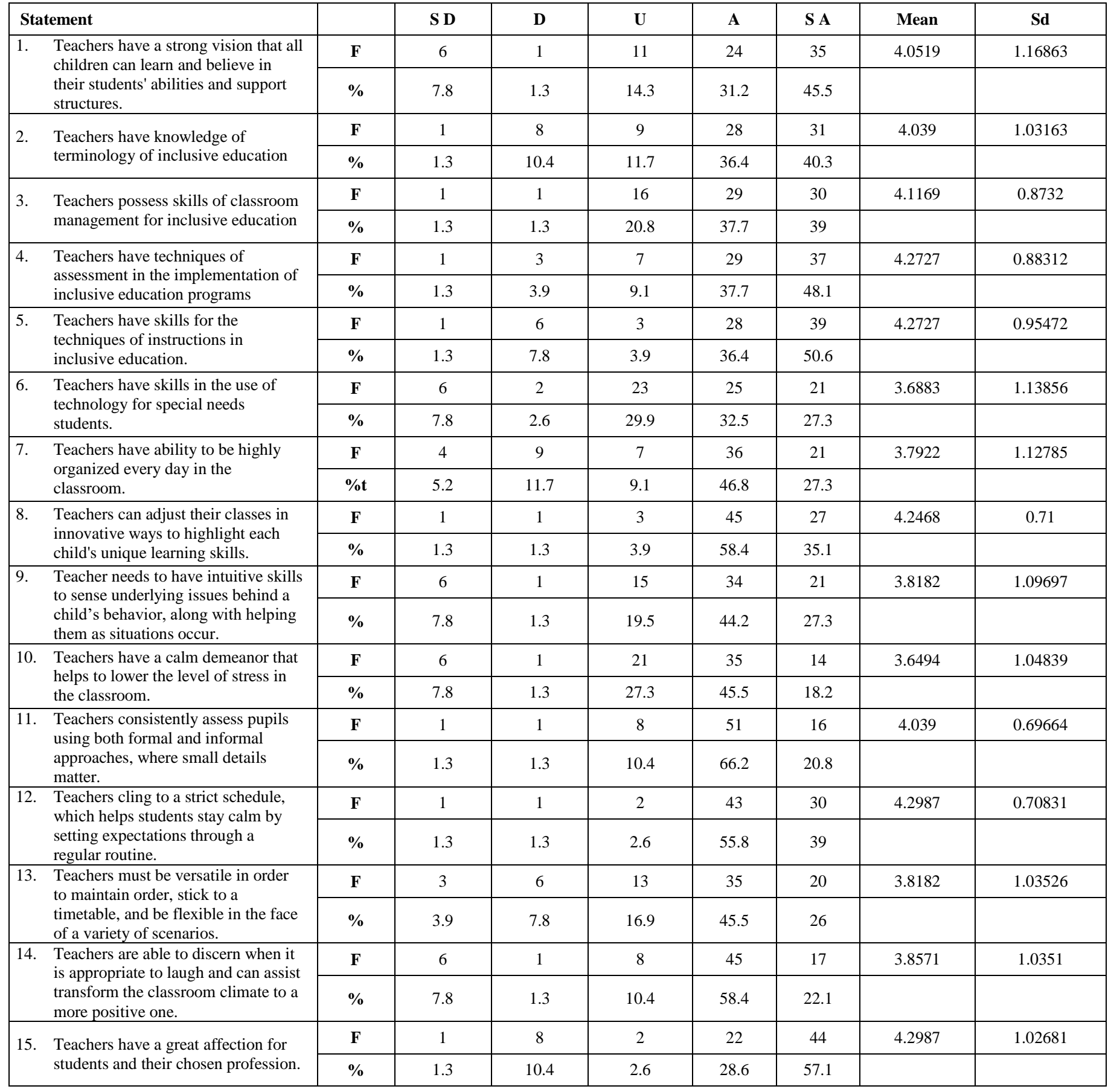


The study findings in Table 4 revealed that $59(76.7 \%)$ of the respondents agreed with the statement that Teachers have a strong vision that all children can learn and believe in their students' abilities and support structures. $7(9.1 \%)$ of the respondents disagreed. In terms of mean and standard deviation most of respondents agreed that teachers have a strong vision that all children can learn and believe in their students' abilities and support structures (Mean=4.0519, standard deviation=1.16863). Also, 59(76.7\%) of the respondents agreed with the statement that Teachers have knowledge of terminology of inclusive education. However, $9(11.7 \%)$ of the respondents disagreed. In terms of mean and standard deviation majority of the respondents agreed that Teachers have knowledge of terminology of inclusive education $($ mean $=4.039$, standard deviation $=1.03163)$.

Further, 59(76.7\%) of the respondents agreed with the statement Teachers possess skills of classroom management for inclusive education. 2(2.6\%) disagreed with the statement. In terms of mean and standard deviation most of the respondents agreed that Teachers possess skills of classroom management for inclusive education (mean $=4.1169$, standard deviation=0.8732). In addition, 66(85.8\%) of the respondents agreed with the statement that Teachers have techniques of assessment in the implementation of inclusive education programs. Only $6(7.8 \%)$ of the respondents disagreed. In terms of mean and standard deviation majority of the respondents agreed that Teachers have techniques of assessment in the implementation of inclusive education programs (mean=4.2727, standard deviation=0.88312). Furthermore $67(87 \%)$ of the respondents agreed with the statement Teachers have skills for the techniques of instructions in inclusive education. However, $7(9.1 \%)$ of the respondents disagreed. In terms of mean and standard deviation most of the respondents agreed that Teachers have skills for the techniques of instructions in inclusive education (mean $=4.2727$, standard deviation $=0.95472$ ).

Furthermore, the study findings in Table 4.5 revealed that $46(59.8 \%)$ of the respondents agreed with the statement that Teachers have skills in the use of technology for special needs students.8(10.4\%) of the respondents disagreed. In terms of mean and standard deviation majority of respondents agreed Teachers have skills in the use of technology for special needs students $($ Mean $=3.6883$, standard deviation=1.13856). Also, $57(74.1 \%)$ of the respondents agreed with the statement that Teachers have ability to be highly organized every day in the classroom. However, 13(16.9\%) of the respondents disagreed. In terms of mean and standard deviation majority of the respondents agreed that Teachers have ability to be highly organized every day in the classroom (Mean $=3.7922$, standard deviation=1.12785).

Further, $72(93.6 \%)$ of the respondents agreed with the statement that Teachers can adjust their classes in innovative ways to highlight each child's unique learning skills. 2(2.6\%) disagreed with the statement. In terms of mean and standard deviation majority of the respondents agreed that Teachers can adjust their classes in innovative ways to highlight each child's unique learning skills (mean $=4.2468$, standard deviation $=0.71)$. In addition, $56(71.5 \%)$ of the respondents agreed with the statement that Teachers foster a good perception among both regular and disabled students. Only $7(9.1 \%)$ of the respondents disagreed. In terms of mean and standard deviation majority of the respondents agreed that Teachers foster a good perception among both regular and disabled students (mean $=3.8182, \quad$ standard deviation=1.09697). Furthermore 49(63.7\%) of the respondents agreed with the statement that Teachers have a calm demeanor that helps to lower the level of stress in the classroom. However, 7(9.1\%) of the respondents disagreed. In terms of mean and standard deviation majority of the respondents agreed that Teachers have a calm demeanor that helps to lower the level of stress in the classroom (mean=3.6494, standard deviation=1.04839).

Lastly, the study findings in Table 2 revealed that $67(87 \%)$ of the respondents agreed with the statement that Teachers consistently assess pupils using both formal and informal approaches, where small details matter. 2(2.6\%) of the respondents disagreed. In terms of mean and standard deviation majority of respondents agreed that wherever possible, teachers remove structural barriers to allow children with disabilities to move about independently (Mean=4.039, standard deviation=0.69664). Also, 73(94.8\%) of the respondents agreed with the statement that Teachers cling to a strict schedule, which helps students stay calm by setting expectations through a regular routine. However, 18(23.4\%) of the respondents disagreed. In terms of mean and standard deviation most of the respondents agreed that Teachers cling to a strict schedule, which helps students stay calm by setting expectations through a regular routine (Mean =4.2987, standard deviation $=0.70831$ ).

Further, 55(71.5\%) of the respondents agreed with the statement that Teachers must be versatile in order to maintain order, stick to a timetable, and be flexible in the face of a variety of scenarios. $9(11.7 \%)$ disagreed with the statement. In terms of mean and standard deviation majority of the respondents agreed that Teachers must be versatile in order to maintain order, stick to a timetable, and be flexible in the face of a variety of scenarios (mean $=3.8182$, standard deviation=1.03526). In addition, $62(80.5 \%)$ of the respondents agreed with the statement that Teachers are able to discern when it is appropriate to laugh and can assist transform the classroom climate to a more positive one. Only $7(9.1 \%)$ of the respondents disagreed. In terms of mean and standard deviation majority of the respondents agreed that Teachers are able to discern when it is appropriate to laugh and can assist transform the classroom climate to a more positive one (mean $=3.8571$, standard deviation=1.0351). Furthermore 66(85.7\%) of the respondents agreed with the statement that Teachers have a great affection for students and their chosen profession. However, 9(11.7\%) of the respondents disagreed. In terms of mean and standard deviation most of the respondents agreed that Teachers have a great affection for 
students and their chosen profession (mean=4.2987, standard deviation=1.02681).

\section{CONCLUSION AND RECOMMENDATIONS}

\section{Conclusion}

The study concluded that teachers in an inclusive school should have a strong vision that all children can learn and believe in their abilities. Teachers should possess skills in classroom management for inclusive education. They should also possess techniques of assessment in the implementation of inclusive education programs, a study has found. Teachers should have the ability to be highly organized every day in the classroom. Teachers must foster a good perception among both regular and disabled students. Teachers need to have skills in the use of technology for special needs students since it helps break down barriers for people with disabilities. Love mobilizes important attention resources, both in class and out of interaction with students. Great affection seems likely to influence children in their learning and development positively. This is an engaging perception for teachers who wish to engage their students in activities that make them feel good about themselves.

These study findings are in accordance to Pitten et al. (2018) who noted that the inclusion of students with disabilities in regular school classrooms requires regular school teachers to redesign their abilities to react to the new difficulties given by their changing roles and responsibilities. Teachers need to have skills to handle students with disabilities in a school with inclusive education. Further, Majoko (2019) study findings urged that teacher are expected to resolve issues and give answers for difficulties presented by unique necessities learners who may fluctuate in their ability levels. Further Roose et al. (2019) revealed that inclusion requires an enormous vision and explicit skills for teachers. The teachers need to realize that variety is available in the classroom and take care of assorted needs. Ainscow (2020) results concurred with the current study that each teacher should know how to be inclusive by ensuring equality, quality, and equity for successful implementation of inclusive education. Abudu (2018) stresses that, in inclusive instruction classrooms, regular school teachers should teach 'content' in a different way. It should be integrative, adaptable, and interdisciplinary. The teachers should comprehend the assets accessible to assist them in working with understudies with inabilities.

When teachers do not have uniformity of the concept inclusion and improper or totally lack of training on inclusion, then its implementation among the learners becomes a challenge. Adewumi and Mosito, (2019) affirms the idea of improper inclusion by asserting that majority teachers are not well informed or trained when inclusion began because of little or no training at all. Full inclusion may not be implemented without making preparatory training because training makes things be done in a near uniformity version. There could be discrepancy among teachers about their roles in that the role of the regular education teacher verses the role of a special education teacher in an inclusive classroom is not clear due to lack of clarity of the term inclusion hence the discrepancy that leads to confusion.

Furthermore, the study findings were in accordance with Donohue and Bornman (2014), teachers in South Africa lack the knowledge, skills, and training for the effective implementation of inclusive education. The teachers clearly lack knowledge of concerns concerning inclusive education. Furthermore, the teachers felt unprepared and unequipped to teach in inclusive classrooms due to a lack of training, time, huge classes, and teacher experience. Fear of not being able to manage variety led to emotions of pessimism and learners being referred for assessments by specialists and placements in special programmes, both of which have a detrimental influence on inclusive learning. Misconceptions and preconceptions about learners with unique educational needs and the possible impacts of inclusion on these learners and other students in the classroom contribute to negative perceptions and labelling.

\section{Recommendations and Implication of the Study}

The study recommends that the teachers receive in-service training to ensure that they have a strong vision of all children being able to learn and believe in their kids' talents. For inclusive education, teachers need to have classroom management abilities. Every day in the classroom, teachers should be able to be very structured. Teachers must encourage both ordinary and disabled students to have a positive perception.

The Ministry of Education must implement an inclusive education policy that will effectively implement an inclusive education system. This policy should define measures for providing educational support to students who face hurdles to learning and development. They can accomplish these goals by establishing an inclusive education and training system. The Ministry of Education should support in-service training for inclusive education.

\section{REFFERENCES}

[1] Ainscow, M. (2020). Promoting Inclusion and Equity in Education: Lessons from International Experiences. Nordic Journal of Studies in Educational Policy, 6(1), 7-16.

[2] Apuke, O. D. (2017). Quantitative Research Methods: A Synopsis Approach. Kuwait Chapter of Arabian Journal of Business and Management Review, 33(5471), 1-8.

[3] Gidlund, U., \& Boström, L. (2017). What Are Inclusive Didactics? Teachers' Understanding of Inclusive Didactics for Students with EBD in Swedish Mainstream Schools. International Education Studies, 10(5), 87-99.

[4] Kiplagat, H., Syonthi, J., \& Situma, J. (2019). Learning Challenges to Inclusive Learning in an ECDE Centers in Eldoret East Sub-County, Uasin Gishu County, Kenya. International Journal Of Academic Research In Business And Social Sciences, $9(11)$.

[5] Majoko, T. (2019). Teacher Key Competencies for Inclusive Education: Tapping Pragmatic Realities of Zimbabwean Special Needs Education Teachers. SAGE Open, 9(1), 21-58.

[6] Mngo, Z. Y., \& Mngo, A. Y. (2018). Teachers' Perceptions of Inclusion in A Pilot Inclusive Education Program: Implications for 
Instructional Leadership. Education Research International, 8(2), $30-46$.

[7] Pitten Cate, I. M., Markova, M., Krischler, M., \& KrolakSchwerdt, S. (2018). Promoting Inclusive Education: The Role of Teachers' Competence and Attitudes. Insights into Learning Disabilities, 15(1), 49-63.

[8] Roose, I., Vantieghem, W., Vanderlinde, R., \& Van Avermaet, P. (2019). Beliefs as Filters for Comparing Inclusive Classroom Situations. Connecting Teachers' Beliefs About Teaching Diverse Learners to Their Noticing of Inclusive Classroom Characteristics in Videoclips. Contemporary Educational Psychology, 56(6), 140151 .
[9] Round, P. N., Subban, P. K., \& Sharma, U. (2016). 'I don't have time to be this busy. 'Exploring the concerns of secondary school teachers towards inclusive education. International Journal of Inclusive Education, 20(2), 185-198.

[10] Sharma, U., Shaukat, S., \& Furlonger, B. (2015). Attitudes and self-efficacy of pre-service teachers towards inclusion in Pakistan. Journal of research in special educational needs, 15(2), 97-105.

[11] Varcoe, L., \& Boyle, C. (2014). Pre-service primary teachers' attitudes towards inclusive education. Educational Psychology, 34(3), 323-337.

[12] Wiggins, G. (2012). Seven keys to effective feedback. Feedback, 70(1), 10-16. 